\title{
Glucomannan prevents postprandial hypoglycaemia in patients with previous gastric surgery
}

\author{
W P M HOPMAN, P G M P HOUBEN, P A J SPETH, \\ AND C B H W LAMERS \\ From the Division of Gastroenterology and Department of Medicine, Radboud Hospital, University of \\ Nijmegen, Nijmegen, The Netherlands and Department of Gastroenterology and Hepatology, University \\ Hospital, Leiden, The Netherlands
}

SUMmary Glucomannan $\left(\right.$ Propol $\left.^{\mathrm{R}}\right)$, a potent gel forming dietary fibre, was added to a carbohydrate rich breakfast in eight patients with previous gastric surgery suffering from postprandial hypoglycaemia. Addition of only $2.6 \mathrm{~g}$ and $5.2 \mathrm{~g}$ glucomannan to the meal dose dependently improved reactive hypoglycaemia from $2 \cdot 3(0 \cdot 2) \mathrm{mmol} / \mathrm{l}$ to $3 \cdot 3(0 \cdot 2) \mathrm{mmol} / \mathrm{l}(\mathrm{p}<0.0005)$ after $2.6 \mathrm{~g}$ and $4 \cdot 1(0 \cdot 2) \mathrm{mmol} / \mathrm{l}(\mathrm{p}=0.0005)$ after $5 \cdot 2 \mathrm{~g}$, and decreased postprandial rise in plasma insulin $(p<0.05)$. Expiratory breath hydrogen excretion tended to decrease reflecting improvement of carbohydrate metabolism. Addition of glucomannan to an intraduodenal sucrose solution significantly raised plasma glucose nadirs, indicating glucomannan to be effective during the intestinal phase. It is concluded that small amounts of glucomannan may be beneficial to patients with reactive postprandial hypoglycaemia, without the disadvantage of unpalatability and carbohydrate malabsorption.

About $10-20 \%$ of patients with previous gastric surgery suffer from the dumping syndrome.' Symptoms caused by hypoglcaemia are frequently referred to as late dumping. These symptoms occur one to three hours after a meal and consist of the feeling of warmth, sweating, shakiness, dizziness, and difficulty in concentration. ${ }^{\prime 2}$ Hyperinsulinaemia caused by rapid postprandial rise of blood glucose concentration and abnormal gut endocrine response precipitated by rapid gastrointestinal transit of food substances is thought to be the cause of this reactive hypoglycaemia several hours after a meal. ${ }^{1-4}$

Symptoms can be alleviated by the use of frequent small meals, addition of $\alpha$-glycoside hydrolase inhibitors or addition of dietary fibres with gel forming properties to the meal. ${ }^{15-7}$ Treatment often fails, however, because of side effects or affords incomplete relief. ${ }^{7}$ This study reports on the effect of glucomannan $\left(\right.$ Propol $^{\mathrm{R}}$ ) added to a normal carbo-

Address for correspondence: Wim P M Hopman, MD. PhD, Division of Gastroenterology. Radboud Hospital. University of Nijmegen, $6500 \mathrm{HB}$ Nijmegen, The Netherlands.

Received for publication 29 January 1988. hydrate rich breakfast on plasma glucose, plasma insulin, and breath hydrogen excretion in patients with reactive hypoglycaemia after gastric surgery. Furthermore, in healthy volunteers plasma glucose concentrations after intraduodenal instillation of sucrose with and without glucomannan were studied in order to elucidate the effect of the fibre on carbohydrate metabolism during the intestinal phase.

\section{Methods}

PATIENTS

Eight patients participated in the study (seven men, one woman; mean age 43 years, range $22-62$ ). All had been operated upon for peptic ulcer at least one year before. Six patients underwent a partial gastric resection, one patient a selective vagotomy with gastroenterostomy, and one a truncal vagotomy with pyloroplasty. The patients were selected on the basis of having a history suggestive of postprandial hypoglycaemia, a plasma glucose of less than $3.0 \mathrm{mmol} / \mathrm{l}$ at least 60 minutes after ingestion of $50 \mathrm{~g}$ glucose $/ \mathrm{m}^{2}$ 
body surface, and hypoglycaemic symptoms at least 60 minutes after the oral glucose load. Each patient was studied on three occasions.

On each occasion they ingested a standard breakfast within 15 minutes. In random order and in a double blind fashion to the breakfast was added $5 \cdot 2 \mathrm{~g}$ placebo, $2.6 \mathrm{~g}$ glucomannan plus $2.6 \mathrm{~g}$ placebo, and $5 \cdot 2$ g glucomannan (Propol $^{\mathrm{k}}$, Pharmacia, Woerden, The Netherlands). The placebo consisted of propol made water insoluble by treatment with a $30 \%$ ethanol sodium hydroxide water solution followed by neutralisation with hydrochloric acid and dehydration to powder form. The breakfast consisted of three slices of bread with $20 \mathrm{~g}$ butter, $42 \mathrm{~g}$ marmalade, and $10 \mathrm{~g}$ sugar, $100 \mathrm{ml}$ tea containing $10 \mathrm{~g}$ sugar, and 150 $\mathrm{ml}$ milk. The breakfast contained $88 \mathrm{~g}$ carbohydrate, $18.5 \mathrm{~g}$ fat and $11 \mathrm{~g}$ protein. Glucomannan or placebo was administered as a powder substance carefully mixed with the butter. Blood samples were drawn through a butterfly cannula in the forearm at $-5,0$, $15,30,45,60,75,90,105,120,135,150,165$, and 180 minutes. Before ingestion of the meal and at 30 minutes intervals during the study, end expiratory gas samples were obtained for measurement of breath hydrogen. ${ }^{*}$

In addition six healthy volunteers (two men, four women; mean age 23 years, range 21-25) were studied on two mornings after an overnight fast. Blood samples for measurement of plasma glucose were drawn before and at 10 minutes intervals during the next three hours after rapid (one to two minutes) intraduodenal instillation of $30 \mathrm{~g}$ sucrose in $120 \mathrm{ml}$ water to which either $5.2 \mathrm{~g}$ placebo or $5.2 \mathrm{~g}$ glucomannan was added again in a double blind fashion. Plasma glucose was measured by the method of Hoffman and plasma insulin by radioimmunoassay. ${ }^{10}$

Results were expressed as the mean (1) (SE). Plasma glucose nadir was defined by the lowest individual postprandial value. Integrated insulin and breath hydrogen responses were determined by calculating the area under the curve after subtraction of basal value. Statistical analysis was done by Student's $t$ test for paired results. All patients and healthy volunteers gave informed consent before entering the study.

\section{Results}

After an initial rise in plasma glucose during the control study without glucomannan to a mean value of $8 \cdot 3(0 \cdot 6) \mathrm{mmol} / \mathrm{l}$, plasma glucose concentrations fell sharply to levels below $3.5 \mathrm{mmol} / \mathrm{l}$ from 105 to 180 $\mathrm{min}$ in the late postprandial period (Fig. 1). This reactive hypoglycaemia significantly improved after addition of $2.6 \mathrm{~g}$ glucomannan to the meal at 135 ,
150 , and 165 minutes $(\mathrm{p}<0 \cdot(01-\mathrm{p}<0 \cdot() 5)$, and from 9() to 180 minutes $(p=0 \cdot 0001-p<0 \cdot(05)$ after ingestion of the meal with $5 \cdot 2 \mathrm{~g}$ glucomannan (Fig. 1). After glucomannan plasma glucose nadirs dose dependently increased from $2 \cdot 3(0 \cdot 2) \mathrm{mmol} / \mathrm{l}$ after placebo, to $3 \cdot 3(0 \cdot 2) \mathrm{mmol} / \mathrm{l}$ after $2 \cdot 6 \mathrm{~g}$ of the fibre $(\mathrm{p}<0.0005 \mathrm{v}$ control), and to $4 \cdot 1(0.2) \mathrm{mmol} / \mathrm{l}$ after $5.2 \mathrm{~g}$ glucomannan $(\mathrm{p}<0.0005 \vee$ control, $\mathrm{p}<0.01 \vee 2.6 \mathrm{~g}$ glucomannan; Figure. 2).

Addition of glucomannan to the meal significantly reduced plasma insulin peak concentrations from 197 (36) $\mathrm{mU} / \mathrm{l}$ after placebo to $122(30) \mathrm{mU} / \mathrm{l}$ after $2.6 \mathrm{~g}$ $(\mathrm{p}<0 \cdot 05)$, and to $99(27) \mathrm{mU} / \mathrm{l}$ after $5.2 \mathrm{~g}$ glucomannan $(\mathrm{p}<0.05$; Figure 2$)$. Integrated plasma insulin secretions were $9843(3478) \mathrm{mU} / \mathrm{l} 180 \mathrm{~min}$ after placebo, $7153(2107) \mathrm{mU} / 180 \mathrm{~min}$ after $2.6 \mathrm{~g}$ glucomannan and $4052(990) \mathrm{mU} / 1180 \mathrm{~min}$ after $5 \cdot 2 \mathrm{~g}$ glucomannan. The differences between glucomannan and placebo just failed to reach statistical significance $(p=0.07$ after 2.6 and $p=0.06$ after $5.2 \mathrm{~g}$ glucomannan). During placebo six of the patients had an increase in breath hydrogen production of more than $15 \mathrm{ppm}$, three after $2.6 \mathrm{~g}$ glucomannan and only one after $5.2 \mathrm{~g}$ of the fibre. Integrated breath hydrogen excretions were 3998 (2162) ppm $180 \mathrm{~min}$ after placebo, $2003(1350) \mathrm{ppm} 180 \mathrm{~min}$ after $2.6 \mathrm{~g}$ glucomannan and $-560(742) \mathrm{ppm} 180 \mathrm{~min}$ after $5 \cdot 2 \mathrm{~g}$ glucomannan. The differences between glucomannan and placebo were not significantly different $(p=0.43$ and $p=0.09$ respectively). After placebo six patients experienced complaints during the late postprandial period varying from somnolence, dizziness, restlessness, a feeling of warmth and sweating, and a desire to lie down. On both doses of glucomannan the patients subjectively benefited from the treatment, especially in regard to complaints of dizziness, palpitation, and sweating during the late postprandial period. The $5 \cdot 2 \mathrm{~g}$ dose of glucomannan, however, induced a feeling of epigastric fullness in the majority of the patients.

After intraduodenal instillation of sucrose with $5.2 \mathrm{~g}$ placebo plasma glucose rose to a mean peak level of $7 \cdot 2(0 \cdot 1) \mathrm{mmol} / \mathrm{l}$ followed by plasma glucose concentrations below basal value after 40 minutes (Fig. 1). This reactive hypoglycaemia observed during the placebo study was completely abolished by addition of glucomannan to the intraduodenal solution (Fig. 1). Plasma glucose nadirs significantly increased from $2 \cdot 6(0 \cdot 3) \mathrm{mmol} / \mathrm{l}$ after placebo to 3.5 $(0 \cdot 1) \mathrm{mmol} / \mathrm{l}$ after glucomannan $(\mathrm{p}<0 \cdot 05)$.

\section{Discussion}

Propol $^{R}$ is a recently developed dietary fibre with much stronger gel forming properties than pectin or guar. "I2 It is an unabsorbable polysaccharide pre- 

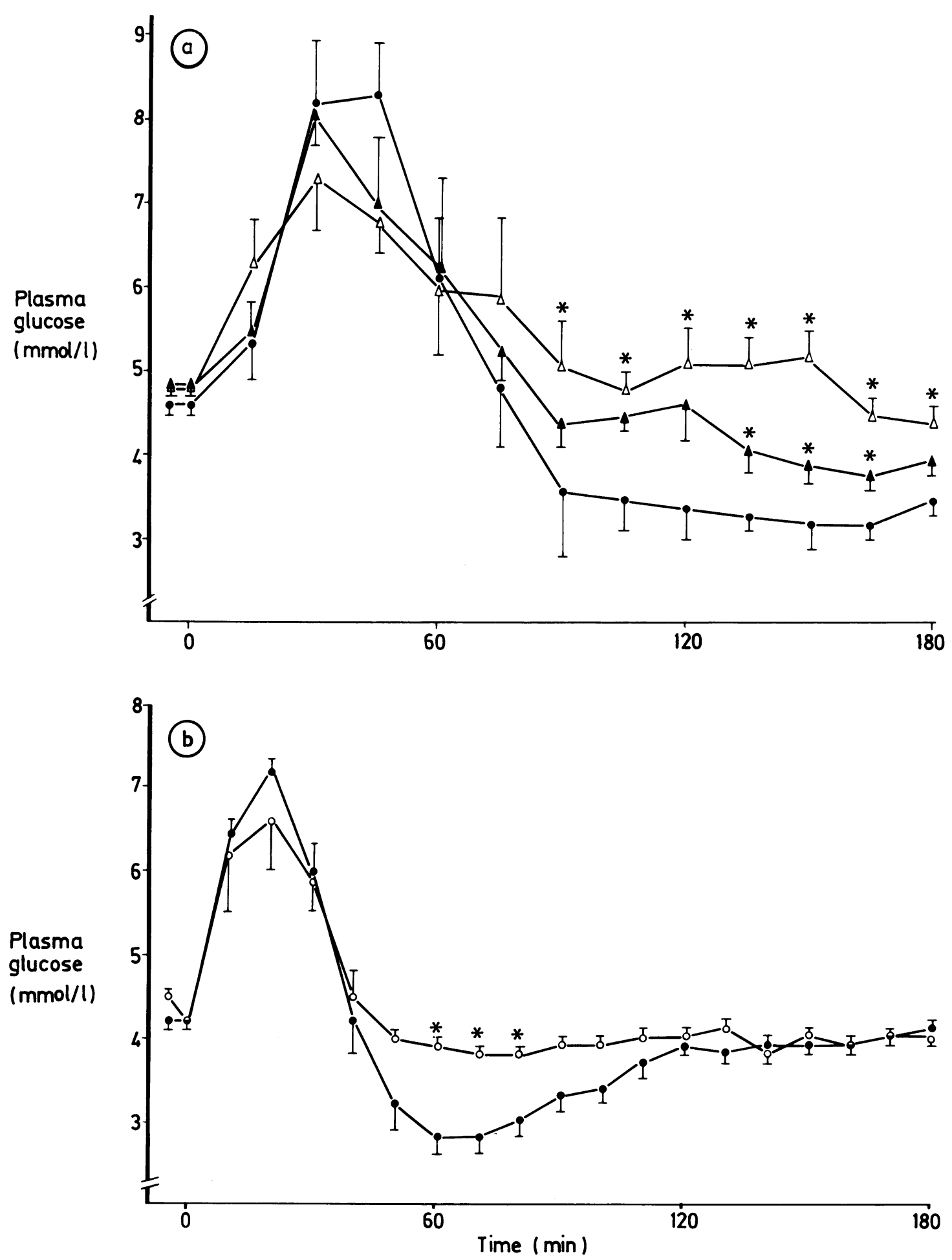

Fig. 1 Upper panel: plasma glucose in response to ingestion of a carbohydrate rich breakfast with $5 \cdot 2 \mathrm{~g}$ placebo $(\bullet), 2 \cdot 6 \mathrm{~g}$ Propol ${ }^{\circledR}$ and $2.6 \mathrm{~g}$ placebo $(\Delta)$, and $5 \cdot 2 \mathrm{~g}$ Propol ${ }^{\circledR}(\triangle)$ in eight patients with previous gastric surgery. ${ }^{*}$ denote significant differences from $5 \cdot 2 \mathrm{~g}$ placebo. Lower panel: plasma glucose in response to intraduodenal instillation of a sucrose solution with $5 \cdot 2 \mathrm{~g}$ placebo $(\mathbf{O})$ and with $5 \cdot 2 \mathrm{~g}$ Propol ${ }^{\circledR}(\mathrm{O}) .{ }^{*}$ denote significant differences from placebo. 

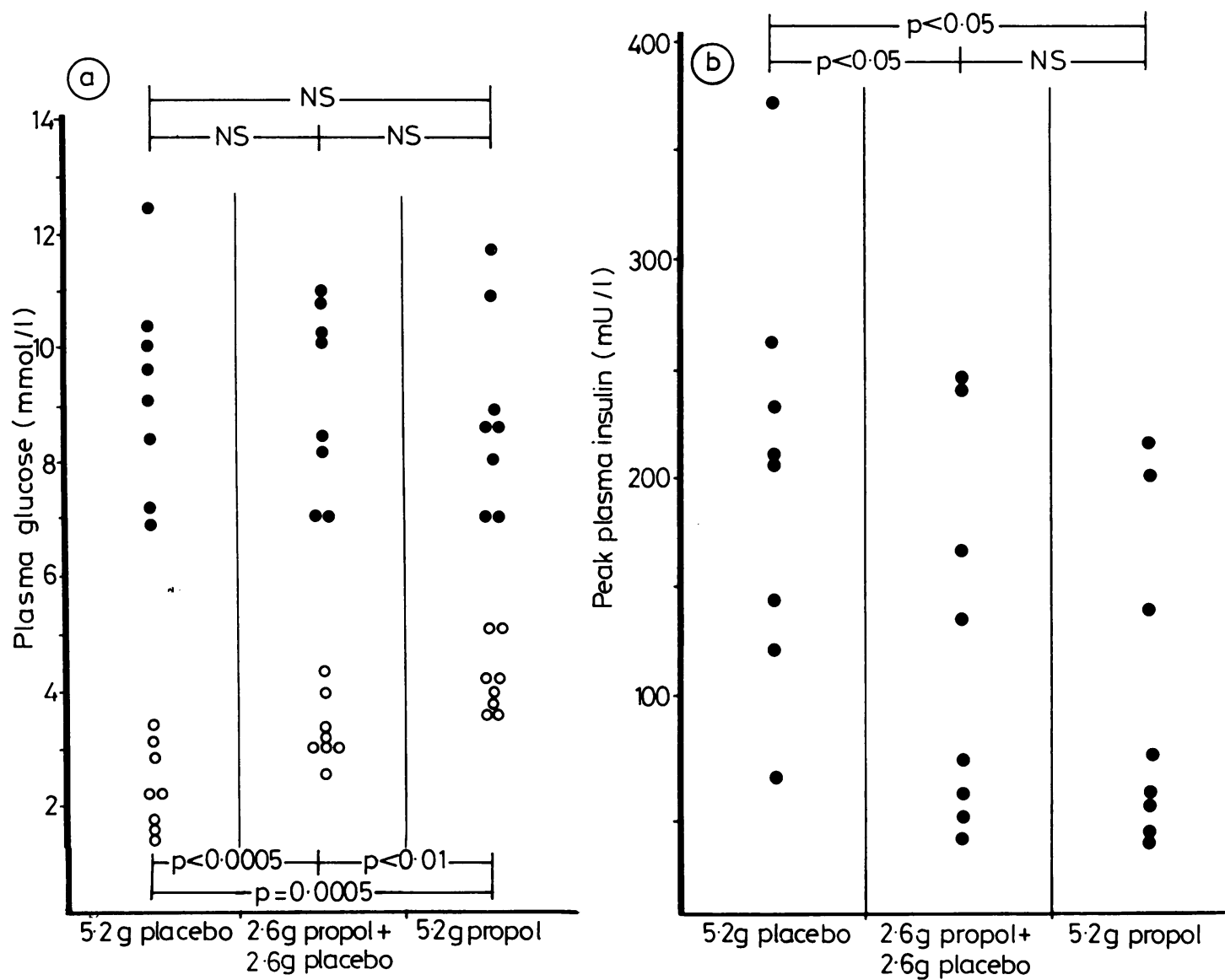

Fig. 2 Effect of $5 \cdot 2 \mathrm{~g}$ placebo, $2.6 \mathrm{~g}$ Propol ${ }^{\circledR}$ and $2.6 \mathrm{~g}$ placebo, and $5 \cdot 2 \mathrm{~g}$ Propol ${ }^{\circledR}$ on plasma glucose peaks (O) and plasma glucose nadirs (O; left panel), and on plasma insulin peaks (right panel) in eight gastric surgery patients.

pared from tubers of the amorphophallus konjac plant consisting of glucose and mannose in the molar ratio 1:1·6. "12 Glucomannan has been shown to reduce postprandial glucose concentrations in normal volunteers and in patients with type II diabetes. ${ }^{112}$

The present study shows that glucomannan is a very potent fibre for the prevention of reactive hypoglycaemia in patients operated upon for peptic ulcer disease. Addition of only $2.6 \mathrm{~g}$ or $5.2 \mathrm{~g}$ to a carbohydrate rich breakfast significantly improved plasma glucose concentrations. Other dietary fibres such as pectin have to be ingested in much larger quantities of about $14.5 \mathrm{~g}$ in order to be effective. ${ }^{35}$ Another disadvantage of pectin is that it is poorly tolerated, because of its unpleasant taste and adherence to the palatum. Glucomannan, on the other hand, is tasteless and does not adhere to the palatum. $\alpha$-Glycoside hydrolase inhibitors have been recommended in patients suffering from reactive hypoglycaemia. ${ }^{67}$ These substances induced serious side effects, however, because of malabsorption of carbohydrates. ${ }^{713}$ In contrast, the low and high dose of glucomannan reduced malabsorption of carbohydrates in three and five of six patients, respectively, as reflected by breath hydrogen excretion in this study.

The mechanism of action of gel forming fibres is related to the ability to increase the viscosity of the gastrointestinal contents and thus interfering with motility and absorption. An inhibitory effect of dietary fibre on gastric emptying has been shown in some,$^{1+15}$ but not all ${ }^{1617}$ studies. In fact, in one of the studies the authors claimed a greater role of delayed small bowel passage than of abnormal gastric emptying in the mechanism whereby gel forming fibres influence absorption of nutrients. ${ }^{17}$ With regard to our study, it is unlikely that in the gastrectomised 
patients glucomannan exerts its effect by delaying gastric emptying. A delay of gastric emptying by glucomannan may have played a role in the two vagotomised patients without gastrectomy, however. ${ }^{16} 18$ The present finding that glucomannan affects absorption of an intraduodenal sucrose load points to an impaired absorption within the intestine itself and is in agreement with the results of several animal studies. ${ }^{1223}$ The reduced absorption may be caused either by an altered diffusion rate or by binding to fibre constituents. ${ }^{19}$ At the intestinal level gel forming fibres probably act mainly by increasing the unstirred layer resistance to diffusion. ${ }^{21} 22$

In conclusion, glucomannan dose dependently prevents postprandial hypoglycaemia in patients with previous gastric surgery without induction of carbohydrate malabsorption. Glucomannan is well tolerated and can be used in small quantities in order to be effective.

The authors are indebted to Professors T J Benraad and A P Jansen for laboratory measurements. Propol $^{\mathrm{R}}$ was kindly supplied by Pharmacia, Woerden, The Netherlands. Part of this paper was presented at the autumn meeting of the British Society of Gastroenterology, Newcastle upon Tyne, September 1985.

\section{References}

1 Fromm D. Complications of gastric surgery. In: Dietschy JM, ed. Clinical gastroenterology monograph series. London: John Wiley and Sons, 1977: 7-34.

2 Woodward ER, Neustein CL. The late postprandial dumping syndrome. In: Bushkin FL, Woodward ER, eds. Postgastrectomy syndromes. Philadelphia: WB Saunders, 1976: 28-33.

3 Jenkins DJA, Bloom SR, Albuquerque RH, et al. Pectin and complications after gastric surgery: normalisation of postprandial glucose and endocrine responses. Gut 1980; 21 : 574-9.

4 Lawaetz O, Aritas Y, Blackburn AM, Ralphs DNL. Gastric emptying after peptic ulcer surgery. Some pathophysiological mechanisms of the dumping syndrome. Scand J Gastroenterol 1982; 17: 1065-72.

5 Jenkins DJA, Gassull MA, Leeds AR, et al. Effect of dietary fiber on complications of gastric surgery: prevention of postprandial hypoglycaemia by pectin. Gastroenterology 1977; 72: 215-7.

6 McLoughin JC, Buchanan KD, Alam MJ. A glycosidehydrolase inhibitor in treatment of dumping syndrome. Lancet 1979; ii: 603-5.

7 Speth PAJ, Jansen JBMJ, Lamers CBHW. Effect of acarbose, pectin, a combination of acarbose with pectin, and placebo on postprandial reactive hypoglycaemia after gastric surgery. Gut 1983; 24: 798-802.

8 Metz G, Gassull MA, Leeds AR, Blendis LM, Jenkins DJA. A simple method of measuring breath hydrogen in carbohydrate malabsorption by end-expiratory sampling. Clin Sci Mol Med 1976; 50: 237-40.

9 Hoffman WS. A rapid photoelectric method for the determination of glucose in blood and urine. $J$ Biol Chem 1937; 120: 51-5.

10 Yalow RS. Berson SA. Immunoassay of endogenous plasma insulin in man. J Clin Invest 1960; 39: 1157-75.

11 Doi K, Matsuura M, Kawara A, Uenoyama R, Baba S. Effect of glucomannan (konjac fiber) on glucose and lipid metabolism in normal and diabetic subjects. In: Melish JS, Hanna J, Baba S, eds. Genetic environmental interaction in diabetes mellitus. Proceedings of the third symposium on diabetes mellitus in Asia and Oceania. Oxford: Excerpta Medica, 1981: 306-12.

12 Doi K. Matsuura M, Kawara A, Baba S. Treatment of diabetes with glucomannan (konjac mannan). Lancet 1979; i: 987-8.

13 Caspary WF. Sucrose malabsorption in man after ingestion of $\alpha$-glucosidehydrolase inhibitor. Lancet 1978; i: 1231-3.

14 Sandhu KS, El Samahi MM, Mena I, Dooley CP, Valenzuela JE. Effect of pectin on gastric emptying and gastroduodenal motility in normal subjects. Gastroenterology 1987; 92: 486-92.

15 Holt S, Heading RC, Carter DC, Prescott LF, Tothill P. Effect of gel fibre on gastric emptying and absorption of glucose and paracetamol. Lancet 1979; i: 636-9.

16 Lawaetz O, Blackburn AM, Bloom SR, Aritas Y, Ralphs DNL. Effect of pectin on gastric emptying and gut hormone release in the dumping syndrome. Scand $J$ Gastroenterol 1983; 18: 327-36.

17 Lembcke B, Ebert R. Ptok R, et al. Role of gastrointestinal transit in the delay of absorption by viscous fibre (guar). Hepatogastroenterol 1984; 31: 183-6.

18 Leeds AR, Ralphs DNL, Ebied F, Metz G, Dilawari JB. Pectin in the dumping syndrome: reduction of symptoms and plasma volume changes. Lancet 1981; i: 1075-8.

19 Elsenhans B, Süfke U, Blume R, Caspary WF. The influence of carbohydrate gelling agents on rat intestinal transport of monosaccharides and neutral amino acids in vitro. Clin Sci 1980; 59: 373-80.

20 Elsenhans B, Süfke U, Blume R, Caspary WF. In vitro inhibition of rat intestinal surface hydrolysis of disaccharides and dipeptides by guaran. Digestion $1981 ; 21$ : 98-103.

21 Elsenhans B, Zenker D, Caspary WF, Blume R. Guaran effect on rat intestinal absorption. Gastroenterology 1984; 86: 645-53.

22 Johnson IT, Gee JM. Effect of gel-forming gums on the intestinal unstirred layer and sugar transport in vitro. Gut 1981; 22: 398-403.

23 Vahouny GV. Effects of dietary fiber on digestion and absorption. In: Johnson LR, ed. Physiology of the gastrointestinal tract. New York: Raven Press, 1987: $1623-48$ 